\title{
Resilience: contingency, complexity, and Practice
}

Citation for published version (APA):

Healy, S., \& Mesman, J. (2014). Resilience: contingency, complexity, and Practice. In A. Hommels, J. Mesman, \& W. E. Bijker (Eds.), Vulnerability in Technological Culture: New directions in research and governance. (pp. 155-177). The MIT Press. Inside Technology

https://doi.org/10.7551/mitpress/9209.003.0011

Document status and date:

Published: 01/01/2014

DOI:

10.7551/mitpress/9209.003.0011

Document Version:

Publisher's PDF, also known as Version of record

Document license:

Taverne

Please check the document version of this publication:

- A submitted manuscript is the version of the article upon submission and before peer-review. There can be important differences between the submitted version and the official published version of record.

People interested in the research are advised to contact the author for the final version of the publication, or visit the DOI to the publisher's website.

- The final author version and the galley proof are versions of the publication after peer review.

- The final published version features the final layout of the paper including the volume, issue and page numbers.

Link to publication

\footnotetext{
General rights rights.

- You may freely distribute the URL identifying the publication in the public portal. please follow below link for the End User Agreement:

www.umlib.nl/taverne-license

Take down policy

If you believe that this document breaches copyright please contact us at:

repository@maastrichtuniversity.nl

providing details and we will investigate your claim.
}

Copyright and moral rights for the publications made accessible in the public portal are retained by the authors and/or other copyright owners and it is a condition of accessing publications that users recognise and abide by the legal requirements associated with these

- Users may download and print one copy of any publication from the public portal for the purpose of private study or research.

- You may not further distribute the material or use it for any profit-making activity or commercial gain

If the publication is distributed under the terms of Article $25 \mathrm{fa}$ of the Dutch Copyright Act, indicated by the "Taverne" license above, 


\section{\& Resilience: Contingency, Complexity, and Practice}

Stephen Healy and Jessica Mesman

There are different concepts that contribute to theorizing about vulnerability. "Creative dissent," as the previous chapter shows, is one of them. Similarly, the analysis of "resilience" can contribute to our understanding of vulnerability as it directs our focus on its positive aspects. As such, resilience should not be considered as the oppositional counterpart of vulnerability, but as a relational notion.

Vulnerability, as has been argued in the introduction of this volume, is an emergent system's property. Likewise, resilience is a system's property too. All systems, whether ecosystems, technological systems, economies, corporations, or nations, possess resilience-an ability to recover from disruptions-because without it, they perish. ${ }^{2}$ Resilience, a fundamental principle of systems ecology, has gained prominence in many fields since the early 1970s, including physics, psychology, organizational studies, sociology, aviation studies, and health care management. This has resulted in the identification of many different kinds of resilience, such as institutional resilience (Pidgeon, 1997), coastal resilience (Klein, Smit, Goosen, \& Hulsbergen, 1998), ecological resilience (Gunderson \& Holling, 2001), mental resilience Johnson \& Wiechelt, 2004), disaster resilience (Manyena, 2006), engineering resilience (Gallopín, 2006), and socioeconomic resilience (Klein et al., 1998), to name a few. These involve characterizing resilience as an outcome or process characteristic, as intrinsic or contingent, as a matter of system structure or function, and as a paradigm or "just an expression" (Manyena, 2006). This pervasive ambiguity regarding resilience remains a notable feature of many accounts, particularly popular ones, even though the use of the term has increased markedly
in recent years.

This imprecision is reinforced by a tendency to overlook the normative dimensions of resilience. While certain kinds of resilience, like those of 


\section{Corporeality, Materiality, and Action}

The characterization of resilience in terms of corporeality, materiality, and action makes a fundamental break with "canonical rationality." Such rationality overlooks bodily practices other than those by which cognitive abstractions are understood to take up residence in minds-observation and contemplation. However, "real practices" count because we do not simply absorb cognitive abstractions from observation and contemplation; we develop them as we interact with the many people and things that make up our world.

In the account developed here, we are therefore primarily concerned with interrogate actions, the dynamic practices constitutive of them, and the many corporeal and material considerations that these encompass. We summarize these using the term "practices," intended to mean the dynamic, intersubjective, discursively mediated, yet inherently socio-material interactions between people, and between people and things, rather than simply repetitive bodily actions. It is these "practices and skills which produce people, selves, and worlds" (Thrift, 2000a, p. 216) and which, as a result, constitute both vulnerabilities and resilience. Our account, therefore, focuses upon such practices and the details, and context, of their performance. This view thus replaces the determinate possibilities suggested by RAP with a window onto the contingencies of practice(s), potentially illuminating how they may be better catered for.

Of particular relevance to this emphasis is research suggesting that our species may be "hardwired" for anticipation, movement, and action, rather than contemplation and observation (Thrift, 2000b). Many contemporary contexts center upon skillfully enacted performances requiring rapid, highstakes decision making and complementary suites of complex practices involving interactions between people and, commonly, machines. Hospitals are good examples, especially those involving critical care practices, like emergency wards, neonatal intensive care units, and operating theaters. The remainder of this section illustrates these arguments by focusing upon how vulnerabilities due to fragile lives, risky contingencies, and emotions are managed through fine tuning, improvisation, inborn characteristics, and material and intersubjective interactions in these contexts. 5

In a critical care practice, like a neonatal intensive care unit (NICU), the unexpected and the uncertain reign supreme. One phone call about an admission coming up from the delivery department can change the whole state of affairs on a ward. The admission of a baby sets in motion an ordering process geared toward the infant's incorporation into the everyday practice of the NICU. Within a few minutes, the staff have to stabilize 
of corporeality, materiality, "canonical rationality." Such Ian those by which cognitive lence in minds-observation $s^{\prime \prime}$ count because we do not servation and contemplation; nany people and things that

therefore primarily concerned ices constitutive of them, and rations that these encompass. ctices," intended to mean the ated, yet inherently socio-mateveen people and things, rather these "practices and skills which it, 2000a, p. 216) and which, as $d$ resilience. Our account, theredetails, and context, of their persterminate possibilities suggested gencies of practice(s), potentially red for.

sis is research suggesting that our on, movement, and action, rather irift, 2000b). Many contemporary formances requiring rapid, highary suites of complex practices d, commonly, machines. Hospiinvolving critical care practices, e care units, and operating thetrates these arguments by focuskle lives, risky contingencies, and bi improvisation, inborn characinteractions in these contexts. ${ }^{5}$ tal intensive care unit (NICU), supreme. One phone call about r. department can change the ion of a baby sets in motion an incorporation into the everyantes, the staff have to stabiliz the baby as swiftly and effectively as possible. To be able to define the condition of the baby as precisely as possible, several blood tests are conducted and electrodes positioned on the baby's body. In this way, the staff ensure nonstop information about vital functions, such as heart rate, blood pressure, respiratory rate, saturation, and temperature. An X-ray will help the doctors to take a good look at the baby's lungs and check if the ventilator tube is in the right position. All these efforts result in several lines and tubes that go in and out the incubator and connect the baby's body to a set of machines.

While carefully coordinating their activities, hospital staff focus upon solving the immediate problems that they encounter and, given the fragility of the patient population in critical care areas, this is never simply a matter of solving a patient's medical problem. The required medical interventions necessitate a dynamic, intricate, and ongoing fine tuning of actions and reactions between people, as well as between people and machines, and it is this dynamic web that constitutes both vulnerabilities and resilience. For instance, the vital functions of a premature baby are quite unstable. These kinds of children are insufficiently developed and lack the capacity to selfregulate their body systems effectively. While critical care staff are highly trained and their activities are focused by well-developed and sophisticated protocols, these can never fully account for contingencies. If these protocols are sometimes adequate, when they fail or are inadequate to the challenge on hand, new practices deploying available resources-social and/ or material-have to be rapidly improvised (Conradson, 2003; Harrison, 2000; Mesman, 2008).

Such "dynamic webs," constituted by individuals and the others, including the things with which they interact, emerge from the relational perspective employed here in which practices, or more specifically the details of their performance and those of the contexts in which these pertormances are embedded, are the primary concern. The entire human and non-human "ensemble," including the practices constitutive of it, thus focus this account. Thrift (2000b) discusses these in terms of a "distributed ecology of thought" noting that "[n]ot only do objects make thought do-able but they also very often make thought possible" (p. 38). Intersubiectivity, then, becomes more than simply a human-to-human affair that also encompasses interactions with objects-whether they be tools, complex technological systems, or merely mundane, everyday objects. Such insembles can be understood and analyzed on many levels-subjective, intersubjective, technological, and/or institutional, for example-and in dimensions ranging from spatial, temporal, through to affective ones. 
Returning to critical care practice, this complexity is typified by the problems arising from differences in the available expertise and experience of medical practitioners. The instability of a patient population demands focused concentration from all the staff involved, although the level of knowledge and experience demanded by extremely severe cases is almost always emergent. Because of the rotation of staff, and disciplinary differences between neonatology and cardiology (for example), intensive monitoring, which is aimed at ruling out risks, can itself become a source of vulnerability. The best staff members, whether nursing or medical, cannot be present around the clock, nor are they all equally experienced.

As with Horlick-Jones' (2005) observation that "practical reasoning" does "not . . follow a clear recipe" (p. 265), hospital staff must also "display regard to a far wider range of situational considerations" (p. 266). Vulnerabilities and resilience are constituted through the ways such "situational considerations" come into being and are managed. These considerations, however, encompass not only material and intersubjective interactions between people, and between people and things, but also subjective, inborn characteristics such as temperament and acquired characteristics (Rogers, 1997). In this way, vulnerability and resilience become matters of will and skills. Aside from a patient's individual characteristics, maximal external support can help improve their condition, and nurses play a crucial role in facilitating the recovery process. ${ }^{6}$ Individual resilience, therefore, is never a static matter but always a work in progress.

\section{Summary}

The view of resilience developed here is focused by the practices constitutive of circumstances and the details of these performances: corporeal, socio-material, affective, and cognitive. The management of situational considerations in highly complex contexts like those of hospital critical care practices exemplifies how embodied and circumstantial action and reaction are constitutive of the resilience of particular circumstances. It also suggests that human effectiveness under complex, stressful, and rapidly changing circumstances is something that humans may be biologically attuned to, in contradistinction to the canonical emphasis on contemplation and observation. Contingencies are thus not something to be predicted and planned for in totality, but rather the "expected unexpected," for which the most helpful approach is to have the capacities, as well as an adequately broad and diverse range of resources and skills, at hand to be able to cope as effectively as possible. 
lexity is typified by the ble expertise and expeof a patient population $f$ involved, although the y extremely severe cases tion of staff, and disciirdiology (for example), $t$ risks, can itself become ers, whether nursing or 1or are they all equally

at "practical reasoning" il staff must also "display ations" (p. 266). Vulnere ways such "situational d. These considerations, rsubjective interactions It also subjective, inborn 1 characteristics (Rogers, some matters of will and istics, maximal external rses play a crucial role in nce, therefore, is never a

by the practices constiverformances: corporeal, lagement of situational hose of hospital critical cumstantial action and lar circumstances. It also $\mathrm{x}$, stressful, and rapidly ins may be biologically :mphasis on contemplait something to be pre"expected unexpected," : capacities, as well as an ind skills, at hand to be
Table 8.1

The primary resilience concepts developed for micro-level analysis

\begin{tabular}{|c|c|c|c|}
\hline $\begin{array}{l}\text { Resilience } \\
\text { Concepts }\end{array}$ & Characteristics & Focus on & Context \\
\hline Canonical & $\begin{array}{l}\text { Calculative, rational } \\
\text { actor. }\end{array}$ & $\begin{array}{l}\text { Individual } \\
\text { preferences. }\end{array}$ & $\begin{array}{l}\text { Maximization of } \\
\text { individual welfare. }\end{array}$ \\
\hline $\begin{array}{l}\text { Relational } \\
\text { perspective }\end{array}$ & $\begin{array}{l}\text { Circumstantial } \\
\text { attention to the } \\
\text { co-constitution of } \\
\text { corporeality, } \\
\text { materiality, affect, \& } \\
\text { anticipation. }\end{array}$ & $\begin{array}{l}\text { The performance of } \\
\text { situated practices } \\
\text { and contingencies. }\end{array}$ & $\begin{array}{l}\text { The performative } \\
\text { character of } \\
\text { circumstance. } \\
\text { Interdependencies } \\
\text { with other levels }\end{array}$ \\
\hline
\end{tabular}

It is important to reemphasize that our concern is with practices interpreted as socio-material ensembles in which human and non-human entities are understood to be constituted by and through the relations between them, rather than existing a priori of them. Effective insights regarding situathe circumstantial elements ind the illumination of the relations between cally, embodied and affective which resilience emerges, including, specifiHowever, it needs to be chapter, that the achievement, as will be underscored in the rest of this structuring and alignment of resilience in practice depends upon the tives arising at higher levels (organe circumstantial elements with impera-

Table 8.1 (after Folke, 2006) prizational and societal, for example). ience concepts developed for microvides an overview of the primary resilstarted by examining the RAP which provel analysis in this section. This to propose a relational perspective on provided a point of departure for us siderations overlooked by RAP. This resilience focused by situational connot only the sociocultural chactional perspective encompasses also the embodied and material chac person-to-person interactions, but people and people and people and the interactions between as an example, that these are all const. We argued, using hospital work particular circumstances.

The Meso-Level: institutions and Socio-Technical Systems

Quantitative Risk Assessment

Quantitative Risk Assessment (QRA) evolved after World War II as a response to the complex challenges of managing-notably, aircraft, spacecraft, and

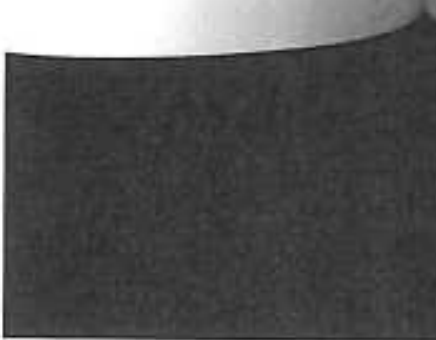


nuclear power stations-and echoes RAP in reflecting an enduring concern with meta-criteria, or computational algorithms, for predicting possible future harm. QRA is, in addition, increasingly applied to problems (e.g., terrorism, ecological issues) for which the bases for calculability are less evident and commonly contested. QRA equates risk with the likelihood of adverse outcomes from particular courses of action, which QRA practitioners commonly regard as an "objective" rendition of the possibility of danger or harm.

This calculative view of risk complements the RAP view of humans as calculative rational actors, and QRA practitioners commonly conflate RAP and QRA (i.e., they assume that "rational" actors will minimize risk as depicted by QRA). However, unlike the optimization criteria of RAP, QRA is focused by the reliability of the maintenance of a meso-level system condition of minimal risk. Although technological systems such as aircraft and nuclear power stations are relatively well specified and bounded and, if not directly amenable to actuarial procedures, lend themselves to quantitative modeling and destructive testing, challenges such as terrorism are quite different. Unbounded and poorly structured, such challenges necessitate a considerably wider range of assumptions that render them calculatively tractable. QRA, however, remains immensely influential because it is understood to be historically validated and also likely because of the beguiling simplicity of its calculative framework.

QRA assumes that contingency can be calculatively resolved by obtaining an optimal, and relatively stable, system in which the potential for harm and injury is reduced to minimal levels. This involves abstracting specific parameters from practical activities, and the contexts in which they occur, and using them to formulate practical interventions into these contexts/activities in an attempt to remove the potential for harm. The process of abstraction overlooks those aspects of activities and contexts deemed of lesser significance, while interventions predicated upon a limited range of parameters can constrain system flexibility. The assumption that stable systems should be maintained once established, for example, has resulted in the recommendation that human action, seen here as a potential disruptive factor, should be kept within prescribed boundaries or replaced by controlled automation (Hollnagel, Woods, \& Leveson, 2006). Inattention to contextual specifics and inflexibility tend to be markers of vulnerability, however, and the QRA literature has tended to downplay resilience and related concepts and emphasize more limited forms of optimality focused on stability rather than change, most notably that of ...... ... . . Liv:.... +n nnform and maintain function). Next, we focus 
ting an enduring concern $s$, for predicting possible upplied to problems (e.g., ; for calculability are less ; risk with the likelihood Iction, which QRA practilition of the possibility of

e RAP view of humans as ; commonly conflate RAP ors will minimize risk as tion criteria of RAP, QRA a meso-level system con'stems such as aircraft and ied and bounded and, if end themselves to quaniges such as terrorism are d, such challenges neces; that render them calcunsely influential because also likely because of the

tively resolved by obtainwhich the potential for This involves abstracting $d$ the contexts in which 1 interventions into these potential for harm. The If activities and contexts is predicated upon a limsxibility. The assumption established, for example, in action, seen here as a prescribed boundaries or Toods, \& Leveson, 2006). ity tend to be markers of has tended to downplay more limited forms of ge, most notably that of unction). Next, we focus on frameworks that are more attentive to contextual specifics and to the dynamics attaching to them, downplayed by $\mathrm{QRA}$ but central to the relational perspective developed in this section.

\section{Risk as Choice versus Risk as Circumstance}

Barry Turner (1994, p. 149) noted that much of the confusion surrounding risk rested on a lack of clarity over "whether risk ... [is] . . something that is taken or ... something that can afflict us"; that is, "[t]he blurred distinction ... between risk as choice and risk as circumstance" (p. 150). QRA/RAP's calculative view of risk focuses the "risk as choice" perspective, which pays limited attention to contextual specifics and has a tendency to inflexibility. Attending more closely to "risk as circumstance," focused by the situational specifics of the circumstances of concern, can moderate such deficiencies. Risk viewed this way problematizes traditional assumptions about rational actors, the calculations that they are assumed to make, and the criteria abstracted from a world assumed to be independent of these actors. Instead, it focuses attention upon what people do, how they do it, and with whom and what they do it. Then, as Gherardi (2004) argues in an organizational context,

[s]afety can ... be viewed as a situated practice, an emerging property of a sociotechnical system, the final result of a collective process of construction, a "doing" which involves people, technologies, and textual and symbolic forms assembled within a system of material relations. (p.62)

While some approaches, such as the organizational risk literature discussed here, have demonstrated something of this sophistication in engaging with the detail of circumstance, other approaches have been more limited.

One of the earliest of these-Charles Perrow's Normal Accidents [1999 (1984)]-had an immediate impact. Perrow argued, with an analysis of the Three Mile Island nuclear plant accident as his primary case study, that interactive complexity and the rigid causal dependence of some technological system components on others (which he called "tight coupling") make "normal accidents" inevitable in such systems. Although Perrow discusses organizational matters, he argues that "high-risk technologies" (that is, ones with high levels of interactive complexity and tight coupling) will inevitably undergo "normal accidents." Other approaches, however, further interrogate the social dimensions of technological systems.

Foster (1993) analyzed complex human-machine systems in terms of social, systemic, economic, environmental, temporal, operational, and physical dimensions to resilience. He argued that the more of these a

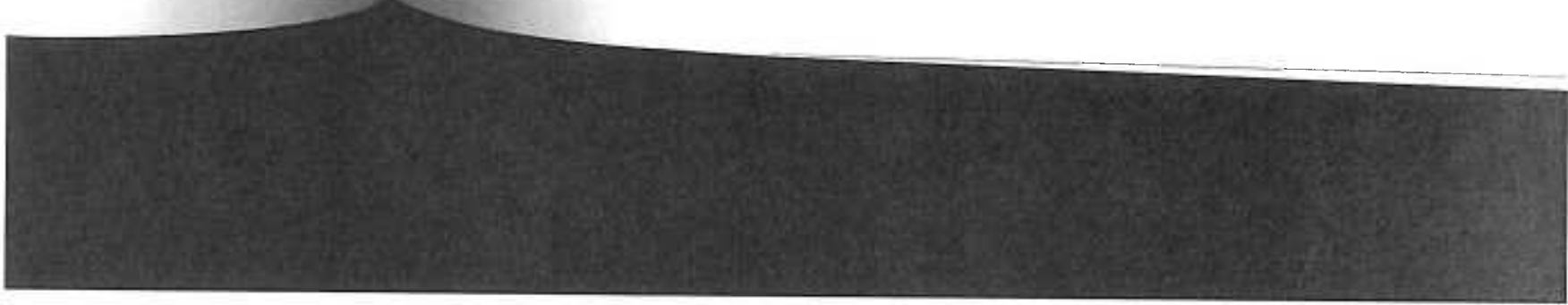


system incorporates, the more it can deal with unanticipated change (p. 59), warning that a focus on achieving reliable systems under normal conditions is "a far more dangerous objective than seeking flexibility and resilience ... inevitably lead[ing] to short term gains . . . at the expense of long term losses" (p. 58). For Foster, the reliability argument is built on an illusion, and the size, complexity, and control structures of today's social and technological systems make them inherently vulnerable. This concern has recently been reflected in the Resilience Engineering approach, ${ }^{7}$ which argues that systems should not only be reliable but resilient (Dekker, 2005).

In this perspective, safety is not a static system feature or an outcome, but rather an emergent property conceived as "a dynamic, interactive, communicative act that is created as people conduct work, construct discourse and rationality around it, and gather experiences from it" (Dekker \& Hollnagel, 2006, p. 6). Safety cannot then be predicted or sustained on the basis of control over certain parts of the system but must involve learning geared to increase a system's adaptive capability. Resilience engineering focuses on the individual human role in socio-technical systems, concentrating on the capacity of practitioners to anticipate and adapt to changes and recover from problems (Dekker, Hollnagel, \& Woods, 2005; Dekker \& Hollnagel, 2006; Hollnagel et al., 2006). It aims to improve practice in such a way that it becomes "better able to recognize, adapt to, and absorb disruptions that would otherwise fall outside the base it was designed to handle" (Dekker $\&$ Hollnagel, 2006). Resilience engineering develops explicit guidance on coping with variation and other challenges that involve trade-offs between situational pressures and safety by monitoring and assessing the adaptive capability of an organization and, therefore, considers anticipation and adaptation core organizational activities.

Resilience engineering presents itself as panacea for the management of safety problems in all kinds of domains, and at all levels. However, it neglects "culture," understood in an anthropological sense "as deeply held complex systems of shared and often tacit meanings and values . . . acquired through many years of socialization [that] inform social action, identity, and belongings" (Rowley \& Waring, 2011). Resilience engineering is still, thus, essentially a "measure and manage" approach to safety that tends to gloss over the cultural fabric of socio-technical systems.

\section{Organizational Culture}

Barry Turner's Man-Made Disasters (Turner, 1978) provided a pioneering approach to organizational and, more broadly, contextual dimensions to 
h unanticipated change (p. systems under normal conseeking flexibility and resilzains . . . at the expense of ility argument is built on an 1 structures of today's social tly vulnerable. This concern ıgineering approach, ${ }^{7}$ which but resilient (Dekker, 2005). stem feature or an outcome, a dynamic, interactive, comIct work, construct discourse ıces from it" (Dekker \& Hollsted or sustained on the basis must involve learning geared ssilience engineering focuses al systems, concentrating on adapt to changes and recover ;, 2005; Dekker \& Hollnagel, ve practice in such a way that , and absorb disruptions that designed to handle" (Dekker levelops explicit guidance on lat involve trade-offs between $\mathrm{Ig}$ and assessing the adaptive $\because$ considers anticipation and

Janacea for the management and at all levels. However, it ropological sense "as deeply acit meanings and values... in [that] inform social action, 2011). Resilience engineering nage" approach to safety that o-technical systems.

1978) provided a pioneering dly, contextual dimensions to risk and disaster, although today Normal Accidents Theory (NAT) is more commonly counterpoised with High-Reliability Theory (HRT).

HRT holds that High-Reliability Organizations (HROs) experience reduced levels of failure and accident because of particular organizational attributes. HRT initially developed from studies of air traffic controllers, aircraft carrier flight deck operations, and electric power system operations (La Porte \& Consolini, 1991).$^{8}$ It was found that, while nominally interactively complex and tight coupled, periods of "high tempo operation" characteristic of the organizations studied involved significant changes to normal operating practices. During these "high tempo" periods, normal organizational hierarchies dissolved, with low-ranking operational personnel commonly guiding operations using personal initiative without structured supervision (although these operations were very demanding and involved high levels of skill). ${ }^{9}$ While various criteria, such as intense regimes of training and socialization, were noted as a marker of HROs, this dissolution of normal decision-making hierarchies was initially seen as an anomaly (La Porte \& Consolini, 1991). Today, however, many supporters of the HRO perspective explain HROs in terms of a straightforward list of criteria commonly subsumed by the term "collective mindfulness" (Weick \& Sutcliffe, 2001). Healy (2006) argues that, rather, HROs are best explained in terms analogous to that developed in the previous section with situated considerations, such as training and socialization, complementing the way "high tempo" operations engage the human predisposition for anticipation and action. HRT has also been criticized for holding to the distinction between technical and social systems and apportioning blame to individuals for error or noncompliance with system demands (Béguin, Owen, \& Wackers, 2009).

The "Swiss cheese model" of James Reason $(1993,2000)$ echoes HRT,10 redirecting explanation away from individuals, practitioners within an organization, to the management of the organization. Reason distinguishes between "active failures" (unsafe acts) and "latent failures" (organizational conditions), and he argues that system errors have their origin in fallible decisions made at the level of management. In his view, latent organizational conditions provide the inevitable "resident pathogens" within a system that give rise to failure and accidents. This model, therefore, holds the promise that the identification of "latent failures" can lead to healthier and therefore safer organizations. Some have argued that the success of this model has inordinately relocated the locus of blame from practitioner to management resulting in inadequate attention to the potential for "active 
errors" (Shorrock, Young, \& Faulkner, 2005; Young, Shorrock, \& Faulkner, 2005).

Turner's analysis in Man-Made-Disasters became a significant contributor to later studies emphasizing organizational culture (see, e.g., Gherardi, 2004; Gherardi, Nicolini, \& Odella, 1998; Hopkins, 2005). Those advocating this view argue that adequate attention to organizational culture/practices can counteract the technological "inevitability" diagnosed by NAT and make organizations safer. Hopkins re-analyzes the Three Mile Island nuclear plant accident to conclude that not only "was [it] not a normal accident ... [but also that] ... [i]t is doubtful if any accident is," and goes on to pin the blame on "sloppy management" (Hopkins, 2001, p. 72). ${ }^{11}$ Diane Vaughan's historical ethnography of the Challenger disaster (1996), which showed the importance of historical knowledge of the context in which accidents occur, also emphasized the significance of organizational culture. Vaughan underlines that a healthy organizational culture is dynamic, and that an organization can become vulnerable when unduly focused on rules and regulations or when other pressures are allowed to create institutional rigidities.

Tumer's attention to situated specifics went beyond narrowly organizational concerns to anticipate matters outlined in the previous section, with observations such as the following:

... the origins of unintended consequences can be located at the physiological level where physical slips and simple typing and speech errors originate, at the psychological or social psychological level from which many individual accidents attributed to "human error" spring, or at the level of organizational processes. (Turner \& Pidgeon, 1997, pp. 149-150)

Man-made disaster (MMD) is thus an analysis of disaster as collective failure, in which attention is redirected away from a narrow focus upon either individual failure or poor management toward broader collective, organizational considerations. Nick Pidgeon (1997) elaborated these ideas to develop the notion of "institutional resilience," emphasizing the "shared cognitions and administrative structures and resources which support, rather than constrict, the development of organizational understandings regarding risk and danger" (Pidgeon \& O'Leary, 2000, p. 18). While overlapping with HRO and the work of Reason (through emphases on management commitment and effective rules and norms, for example), MMD is distinguished by an embrace of contingency and a stress upon effective organizational learning to cater to it. As a result, recent work has examined barriers to organizational learning, in particular informational problems and organizational politics (Pidgeon \& O'Leary, 2000). 
5, Shorrock, \& Faulkner,

a significant contributor see, e.g., Gherardi, 2004; ). Those advocating this xal culture/practices can losed by NAT and make Mile Island nuclear plant lormal accident ... . [but and goes on to pin the ). 72). ${ }^{11}$ Diane Vaughan's 996), which showed the n which accidents occur, culture. Vaughan underlic, and that an organizaon rules and regulations tutional rigidities.

yond narrowly organizahe previous section, with

ted at the physiological level : originate, at the psychologidual accidents attributed to rocesses. (Turner \& Pidgeon,

; of disaster as collective Im a narrow focus upon sward broader collective, 17) elaborated these ideas emphasizing the "shared esources which support, izational understandings 2000 , p. 18). While overgh emphases on manageis, for example), MMD is Id a stress upon effective ecent work has examined : informational problems 2000).
Since 2000 , there has been a growing recognition that human actors deserved more attention, echoing the analysis of the previous section, with some advocating "a reappraisal of human work within fallible systems" (Mesman, 2011; Owen, et al., 2009). This became the focus of a group from different scholarly communities-including cultural history, science and technology studies, human factor analysis, cognitive ergonomics, and complexity theory-who claimed that

there is a need to better understand safety in systems firstly, by analyzing the positive role of human actions with as well as in those systems, and secondly through developing better understandings of the ways in which humans successfully accomplish work in those environments ... and to highlight individual, collective and systemic resources that are used to enhance resilience in acting with complex sociotechnical systems. (Owen et al., 2009, p. 1)

A key insight of these studies is the identification of coordination between the individual and the collective and systemic resources that enhance practices within a complex work environment. Analysis of day-to-day activities shows how those involved rely on different ways of ordering to deploy their knowledge, experience, and technology to preserve adequate levels of safety (e.g., Mesman, 2008, 2009).

\section{Summary}

The meso-level view of resilience described in this section illustrates a shift from calculative approaches such as QRA toward a focus on institutional and contextual considerations, resulting in a recognition of the importance of the resilience of socio-technical systems over their reliability. Contemporary risk and safety studies now place collective, and more broadly, organizational considerations at the forefront of analysis. We argue that the latter approaches-HRT, the work of Reason, Vaughan, Weick, Turner, and Pidgeon, and, most notably, the more recent work sketched above-that give additional, and more sophisticated, attention to organizational and contextual matters provide some continuity with the situational perspective developed in the previous section. Table 8.2 (after Folke, 2006) presents an overview of the resilience concepts developed for meso-level analysis.

\section{The Meta-Level: From Ecosystems to Societies}

\section{Engineering Resilience}

Ecology has traditionally understood resilience as the capacity to resist disturbance and change and, concentrating on near-equilibrium behavior, 
Table 8.2

The primary resilience concepts developed for meso-level analysis

\begin{tabular}{|c|c|c|c|}
\hline $\begin{array}{l}\text { Resilience } \\
\text { Concepts }\end{array}$ & Characteristics & Focus on & Context \\
\hline $\begin{array}{l}\text { Quantitative } \\
\text { risk assessment }\end{array}$ & $\begin{array}{l}\text { Calculative, } \\
\text { predictive } \\
\text { framework }\end{array}$ & $\begin{array}{l}\text { Likelihood of } \\
\text { adverse outcomes }\end{array}$ & $\begin{array}{l}\text { Reliability of large- } \\
\text { scale technological } \\
\text { systems }\end{array}$ \\
\hline $\begin{array}{l}\text { Socio-technical } \\
\text { system studies }\end{array}$ & $\begin{array}{l}\text { Resilience; } \\
\text { interactive } \\
\text { complexity; } \\
\text { adaptive } \\
\text { capability }\end{array}$ & $\begin{array}{l}\text { System properties; } \\
\text { uncertainty and } \\
\text { disturbances; } \\
\text { institutional and } \\
\text { contextual processes }\end{array}$ & $\begin{array}{l}\text { Large-scale socio- } \\
\text { technical systems }\end{array}$ \\
\hline $\begin{array}{l}\text { Organizational } \\
\text { studies }\end{array}$ & $\begin{array}{l}\text { Focus on } \\
\text { management, } \\
\text { organizational } \\
\text { processes and } \\
\text { practices, and } \\
\text { context }\end{array}$ & $\begin{array}{l}\text { Positive } \\
\text { contribution of } \\
\text { humans; } \\
\text { coordination } \\
\text { between individual, } \\
\text { collective, and } \\
\text { systemic resources }\end{array}$ & $\begin{array}{l}\text { Institutional criteria; } \\
\text { organizational culture; } \\
\text { situated specifics and } \\
\text { dynamics }\end{array}$ \\
\hline
\end{tabular}

defined it as the time it takes to return to equilibrium after disturbance. This perspective, termed "engineering resilience" by the ecologist $\mathrm{C}$. S. Holling (1996), assumes that ecosystems possess a single equilibrium, and resilience is equated with what is viewed as this optimal stable state. Natural resource management reflects this in strategies aimed at maximizing human exploitation of ecosystem product through minimizing variability via notions such as "maximum sustainable yield." While such strategies can lead to near-term gains in ecosystem productivity, the minimization of variability involved can result in homogenous ecosystems that, for example, are more vulnerable to pests and disease in the longer term (Folke, 2006). This perspective still commonly informs real-world natural resource management because it complements prevalent economistic imperatives and requires only limited datasets.

This still influential, single-equilibrium view has been replaced by the insight that complex nonlinear systems, such as ecosystems, exhibit multiple equilibriums that can be mapped in terms of domains, defined by key system variables, and across which stability is maintained for periods of time. So, rather than a concern with behavior around particular points of equilibrium, this perspective focuses attention upon behavior 
meso-level analysis

Context

\begin{tabular}{ll}
\hline $\begin{array}{l}\text { of } \\
\text { tcomes }\end{array}$ & $\begin{array}{l}\text { Reliability of large- } \\
\text { scale technological } \\
\text { systems }\end{array}$ \\
perties; & $\begin{array}{l}\text { Large-scale socio- } \\
\text { technical systems }\end{array}$ \\
$\begin{array}{l}\text { and } \\
\text { al and }\end{array}$ & \\
processes & \\
n of & $\begin{array}{l}\text { Institutional criteria; } \\
\text { organizational culture; } \\
\text { situated specifics and } \\
\text { dynamics }\end{array}$ \\
in & \\
dividual, & \\
and & \\
sources & \\
\hline
\end{tabular}

) equilibrium after disturbance. ilience" by the ecologist C. S. ossess a single equilibrium, and ; this optimal stable state. Natustrategies aimed at maximizing through minimizing variability le yield." While such strategies oductivity, the minimization of lous ecosystems that, for examzase in the longer term (Folke, rms real-world natural resource valent economistic imperatives

view has been replaced by the 1ch as ecosystems, exhibit multerms of domains, defined by ability is maintained for periith behavior around particular zuses attention upon behavior at the boundaries of stability domains and upon the dynamics involved in moving from one domain to another. For example, while imperfectly understood, a major concern regarding climate change is the potential for the climate system to "flip" from the present climate pattern to another. ${ }^{12}$ Complex, nonlinear systems require attention be paid to system dynamics and to the complexity, diversity, and variability that sustain resilience at different scales and temporal rates, focusing attention on considerations overlooked by single-equilibrium theory, such as system learning. This is, however, far more demanding on analysts and goes some way toward explaining the continuation, in fields such as natural resource management, of approaches that take engineering resilience as their point of departure.

\section{From a Capacity to Recover to a Capacity to Persist}

Holling pioneered multiple equilibrium theory in ecology in a paper that identified multiple "stability domains" or "basins of attraction" in natural systems, in which he proposed that

Resilience determines the persistence of relationships within a system and is a measure of the ability of these systems to absorb changes of state variables, driving variables, and parameters, and still persist. (Holling 1973, p. 17)

So, as against the engineering resilience focus upon time to return to equilibrium after disturbance, ecological resilience is concerned with maintaining a system within a given stability domain after disturbance. This focuses attention on the system dynamics involved in governing persistence within a given domain. The primary concern, then, becomes buffering capacity, which is the ability to maintain system function in the face of change and disruption, diverting attention to process variables and the potential for unanticipated events. This perspective quickly filtered to other fields, such as anthropological conceptions of culture (Vayda \& McKay, 1975), thus anticipating the attention that Adaptive Environmental Management, discussed later in this chapter, gave to the interaction of social and ecological systems.

Ecological resilience's emphasis upon managing change gives weight to the maintenance of system heterogeneity contrary to engineering resilience's tendency to encourage homogenization and the vulnerabilities this gives rise to. Ecosystem resilience is, however, identified with the functionality of different species groupings (e.g., pollinators, predators, nutrient transporters, etc.), rather than with an undifferentiated species heterogeneity, with some groups identified with different stages of development 
and others critical to overall system dynamics, such as rebuilding system integrity after disturbance and distuption. Different groupings have also been shown to be important to maintaining resilience at different levels and scales, both temporal and spatial.

\section{Systemic Change and Adaptive Capacity}

Inspired, in particular, by the work of Holling (1986) on the adaptive renewal cycle of development and, more recently, the concept of "panarchy" (Gunderson \& Holling, 2001), these newer ideas have directed increasing attention to the human dimensions of ecosystem management focused on what this literature terms "social-ecological systems" (Folke, 2006). The adaptive renewal cycle model identifies four phases of development: exploitation, in which exponential change is the norm; conservation, marked by stasis and rigidity; release or omega phases, marked by readjustment and collapse; and alpha phases, marked by renewal and reorganization. Engineering resilience can be understood to focus on just the first two of these, exploitation and conservation, and overlook release and renewal. The latter two "referred to as 'the backloop' in resilience language ... . [being] . . . just as important as the other two in the overall dynamics" (Folke, 2006, p. 258). In other words, periods of stasis and gradual change coexist with, and complement, periods of rapid transition and systemic change. Panarchy further elaborates on these ideas by proposing that adaptive renewal cycles operate at different scales and rates, and are nested such that intercycle dynamics involving the interdependence of considerations across scales, both spatial and temporal, come into play. After a forest fire, for example, reorganization and renewal draws upon seed banks, structures, and surviving species accumulated in prior growth cycles, and from the wider landscape. Panarchy, therefore, according to Folke (2006), through "the dynamic balance between rapid change and memory, and between disturbance and diversity and their cross-scale interplay ... sustains at the same time as it develops" (p. 259).

This emphasis on cross-scale dynamics throws into question the idea that resilience is about maintaining system function and form, an idea central to both engineering and ecological resilience. Whereas engineering resilience focuses on stability near a point of equilibrium and ecological resilience focuses on persistence within a particular domain, the adaptive view is concerned with ensuring that changes from one domain to another are constructive or desirable. The adaptive view of resilience is thus focused by a systems adaptive capacity, understood as the ability of a system to adapt successfully to change through change in system function, form, or regime 
cs, such as rebuilding system ifferent groupings have also ; resilience at different levels

ling (1986) on the adaptive cently, the concept of "pan? newer ideas have directed as of ecosystem management 1l-ecological systems" (Folke, entifies four phases of develchange is the norm; conserse or omega phases, marked ases, marked by renewal and : understood to focus on just rvation, and overlook release

'the backloop' in resilience is the other two in the over: words, periods of stasis and it, periods of rapid transition ates on these ideas by proposlifferent scales and rates, and volving the interdependence nd temporal, come into play. on and renewal draws upon accumulated in prior growth rchy, therefore, according to e between rapid change and itty and their cross-scale intersps" (p. 259).

Iws into question the idea that ion and form, an idea central e. Whereas engineering resiliilibrium and ecological resilar domain, the adaptive view $\mathrm{n}$ one domain to another are If resilience is thus focused by le ability of a system to adapt tem function, form, or regime shift. Social-ecological systems have become a particular contemporary focus of attention, concerned with adaptive capacity understood in terms of the ability to self-organize and learn. However, this literature commonly overlooks the normative character of "desirable" change trajectories with ecological integrity privileged as the basis for them. ${ }^{13}$ This tension between an emphasis on ecological imperatives and the more recent concern with social and institutional processes remains unresolved. The ecological focus on system outcomes involves a meta-scale view of contingency, and of its management, that is at odds with the necessity for adequate attention to the situated specifics of relevant circumstances and of meso-scale processes outlined in the previous two sections of this chapter.

While work on the adaptive management of social-ecological systems has become increasingly sophisticated in examining broader contextual and organizational matters, these tend to be subordinated to imperatives emerging from systems ecology without acknowledgment, or apparent cognizance, of the broader relevant literature on contextual and/or organizational matters. The challenge that these difficulties pose has recently been thrown into sharp relief by the identification of tensions between the way resilience is conceived in adaptive management and in correlating work on transitions management (e.g., Foxon, Reed, \& Stringer, 2008; Smith \& Stirling, 2008). The latter, focused upon facilitating a socio-technical transition (e.g., to a low-carbon economy) is also informed by complex adaptive systems theory (Foxon et al., 2008, p. 7) and on achieving sustainability, but conceived in terms of different outcomes (i.e., technological transitions) and different processes (Foxon, Reed, \& Stringer, 2008) to adaptive management. So, whereas learning to build resilience to ecological change focuses adaptive management, transition management focuses on facilitating radical, systemic, socio-technical transformation, for which adaptive resilience can be an impediment.

\section{Summary}

This section examined meta-level perspectives on resilience developed in systems ecology, most notably engineering resilience, ecological resilience, and adaptive environmental management. The tensions between this work and that on achieving socio-technical transformation were briefly discussed earlier in the chapter. An admission in a recent discussion of this tension that "the devil is in the detail" (Smith \& Stirling, 2008, p. 3) underscores both the significance of the situational considerations that we identify as a key to the facilitation of resilience in practice and of synergies between the various level-bound analyses of resilience examined. These arguments are 
Table 8.3

The primary resilience concepts developed in ecology (Folke, 2006, p. 259)

\begin{tabular}{|c|c|c|c|}
\hline $\begin{array}{l}\text { Resilience } \\
\text { Concepts }\end{array}$ & Characteristics & Focus on & Context \\
\hline $\begin{array}{l}\text { Engaging } \\
\text { resilience }\end{array}$ & $\begin{array}{l}\text { Relational } \\
\text { perspective; } \\
\text { practical reasoning; } \\
\text { synergies across and } \\
\text { between levels }\end{array}$ & $\begin{array}{l}\text { Embodied, } \\
\text { material, } \\
\text { discursive, and } \\
\text { affective } \\
\text { attributes; } \\
\text { the normative } \\
\text { "framings" of } \\
\text { key stakeholders; } \\
\text { origins of } \\
\text { contingency; } \\
\text { institutional } \\
\text { strictures }\end{array}$ & $\begin{array}{l}\text { Situational specifics } \\
\text { and their } \\
\text { interdependencies } \\
\text { with overall system } \\
\text { dynamics }\end{array}$ \\
\hline $\begin{array}{l}\text { Engineering } \\
\text { resilience }\end{array}$ & $\begin{array}{l}\text { Return time; } \\
\text { efficiency }\end{array}$ & $\begin{array}{l}\text { Recovery; } \\
\text { constancy }\end{array}$ & $\begin{array}{l}\text { Maintenance of } \\
\text { stable equilibrium }\end{array}$ \\
\hline $\begin{array}{l}\text { Ecological/ } \\
\text { ecosystem } \\
\text { resilience; social } \\
\text { resilience }\end{array}$ & $\begin{array}{l}\text { Buffer capacity; } \\
\text { withstand shock; } \\
\text { maintain function }\end{array}$ & $\begin{array}{l}\text { Persistence; } \\
\text { robustness }\end{array}$ & $\begin{array}{l}\text { Multiple } \\
\text { equilibriums; } \\
\text { stability; landscapes }\end{array}$ \\
\hline $\begin{array}{l}\text { Social- } \\
\text { ecological } \\
\text { resilience }\end{array}$ & $\begin{array}{l}\text { Interplay of } \\
\text { disturbance and } \\
\text { reorganization; } \\
\text { sustaining and } \\
\text { developing }\end{array}$ & $\begin{array}{l}\text { Adaptive } \\
\text { capacity of } \\
\text { transformability; } \\
\text { learning; } \\
\text { innovation }\end{array}$ & $\begin{array}{l}\text { Integrated system } \\
\text { feedback; cross- } \\
\text { scale, dynamic } \\
\text { interactions }\end{array}$ \\
\hline
\end{tabular}

taken up in the final section of this chapter. Table 8.3 provides an overview, from Folke (2006), of the different ecological approaches to resilience.

Integrative Framings, Normative Groundings, and Relational Analyses

Resilience is generally assumed to be positive, although examples of negative resilience were noted in the introduction, while we also have examined tensions between resilience as conceived in adaptive management and that in transitions management. Analogous tensions are evident, as discussed elsewhere in this chapter. Reason's argument, for example, that the success of the Swiss cheese model relocated the locus of blame from practitioner to management such that insufficient attention was then paid to the 
Jlogy (Folke, 2006, p. 259)

\begin{tabular}{|c|c|}
\hline on & Context \\
\hline $\begin{array}{l}\text { died, } \\
\text { ial, } \\
\text { sive, and } \\
\text { ve } \\
\text { ites; } \\
\text { Jrmative } \\
\text { ings" of } \\
\text { akeholders; } \\
\text { s of } \\
\text { lgency; } \\
\text { Itional } \\
\text { tres }\end{array}$ & $\begin{array}{l}\text { Situational specifics } \\
\text { and their } \\
\text { interdependencies } \\
\text { with overall system } \\
\text { dynamics }\end{array}$ \\
\hline $\begin{array}{l}\text { ery; } \\
\text { uncy }\end{array}$ & $\begin{array}{l}\text { Maintenance of } \\
\text { stable equilibrium }\end{array}$ \\
\hline $\begin{array}{l}\text { ence; } \\
\text { ness }\end{array}$ & $\begin{array}{l}\text { Multiple } \\
\text { equilibriums; } \\
\text { stability; landscapes }\end{array}$ \\
\hline $\begin{array}{l}\text { ive } \\
\text { ity of } \\
\text { ormability; } \\
\text { ng; } \\
\text { ation }\end{array}$ & $\begin{array}{l}\text { Integrated system } \\
\text { feedback; cross- } \\
\text { scale, dynamic } \\
\text { interactions }\end{array}$ \\
\hline
\end{tabular}

Table 8.3 provides an overview, al approaches to resilience.

\section{ys, and Relational Analyses}

ve, although examples of nega$n$, while we also have examined adaptive management and that sions are evident, as discussed ent, for example, that the suc2 locus of blame from practitioattention was then paid to the potential for "active [practitioner] errors." In each of these cases, tensions emerge because of inattention to normative considerations, most notably the resilience of what, for whom, and at what costs and/or tradeoffs? These are critical matters that any analysis or practically focused initiative concerned with resilience and vulnerability must address explicitly to be effective. It is also notable how these examples all demonstrate interactions between the different levels at which resilience is commonly identified and conceptualized.

These issues are well illustrated in the tensions between adaptive and transitions management. If there are various differences between them, they also have much in common. Both share emphases on iterative learning, the involvement of a wide range of stakeholders, and on institutional change (Foxon et al., 2008). It is these considerations, reflecting Smith and Stirling's observation that "the devil is in the detail," that Foxon, Reed, and Stringer (pp. 16-18) concentrate on in developing a methodology that attempts to reconcile the two. They use "participatory methods ... . to identify the concerns and aspirations of local stakeholders," which are then iteratively integrated with computer models of "possible future social, economic and environmental scenarios" alongside interviews with other stakeholders (p. 16). This methodology thus engages with both the "local" and meta "scenario" level, although also acknowledging the significance of the meso-level through describing these processes as defining "the system boundaries and institutional context" (p. 16). In this case, "participatory methods" illuminate relevant micro-level situated considerations that, iteratively combined with further higher-level considerations, provide a normative grounding for the scenarios developed. So here we have a process predicated on the following:

Establishing a normative framing on the basis of that articulated by key stakeholders

Micro-, meso- and meta-level considerations

The amalgamation of human/non-human considerations (e.g. "social, economic, and environmental")

Reconciling adaptive management with transitions management, then, necessitates an inclusive consultative process designed to normatively reconcile the ecological imperatives of the former with the socio-technical imperatives of the latter, integratively engaging considerations, both human and non-human, at all levels.

The NICU example in section 2 of this chapter similarly highlighted the importance of intimate interdependencies between micro-level 
considerations concerning hospital staff and their relationships, both with each other and with machines, and matters of a more institutional character, such as the detail of staff rosters and management of moments of transition in the life of the hospital. In this case, the normative framing was taken for granted, focusing on the optimization of patient care and welfare (although also extending to the welfare of fellow staff members and the families of patients). Johan M. Sanne's account of bricolage in railway maintenance (see chapter 10, "Vulnerable Practices: Organizing through Bricolage in Railroad Maintenance") argues an analogous requirement for the "local rationality" of railway maintenance workers to be adequately" attuned to the "global rationality" of the railroad organization if vulnerabilities are to be minimized. In other words, while conceptualizations of resilience tend to be level-bound, concentrating on either the micro-, meso-, or macro-level, achieving resilience in practice usually requires coordination involving not only people, but also things across all these levels.

The character of this coordination is critical, however. The examples given previously suggest that resilience and vulnerability not only reside in the detailed dynamic interactions between people, and between people and things, constituting specific circumstances, but also that these articulate broader imperatives. Sanne's railway workers and the hospital workers discussed previously have to pay due attention to the imperatives of the organizations in which they work; otherwise, they and/or their patients might die. Hospital workers are also constrained, and enabled, to fine-tune and improvise within the structures, protocols, and limits generated by the "universalities in medical work" (Berg \& Timmermans, 2000). Similar arguments apply to railway workers, even if "the structures, protocols, and limits" tend to be, for the most part, tacit and informal, rather than "universal" in their case. Sustainability, when it is decided how, and/or if, ecological and broader imperatives such as those related to the transition to a low-carbon economy are to be integrated or privileged, will then have to inform all levels to be effective. People clearly work most effectively with others when they share a shared normative basis for collective action; yet unless this articulates meta-level imperatives and is articulated through and by meso-level organizational considerations, it likely will be ineffective beyond the near term.

Neither contingency nor the details of cross-level coordination are calculatively tractable, making resilience a matter beyond the remit of determinative, calculable frameworks. While these might be effective within well-defined domains and contexts, their deployment should be tempered by due cognizance of their limitations. System vulnerability likely can be 
eir relationships, both with : a more institutional charanagement of moments of ase, the normative framing ization of patient care and of fellow staff members and sunt of bricolage in railway ctices: Organizing through analogous requirement for ? workers to be adequately oad organization if vulner;, while conceptualizations ating on either the micro-, actice usually requires coorings across all these levels. al, however. The examples Inerability not only reside seople, and between people , but also that these articurs and the hospital workers $I$ to the imperatives of the they and/or their patients 1 , and enabled, to fine-tune $s$, and limits generated by Timmermans, 2000). Simif "the structures, protocols, and informal, rather than $t$ is decided how, and/or if, ise related to the transition is privileged, will then have arly work most effectively e basis for collective action; $\mathrm{s}$ and is articulated through $s$, it likely will be ineffective

-level coordination are calbeyond the remit of determight be effective within yment should be tempered vulnerability likely can be lessened by developing better insights regarding the origins of contingency and through giving further attention to ensuring that attempts to cater to these are adequately aligned with higher-level system imperatives. Further insights regarding the origins of contingency require a sustained focus on the situated practices constituting the circumstances of concern requiring attention to not only traditional cognitivist concerns with the contents of minds but also embodied human attributes and skills, interactions both between people and between people and things, and, further, commonly overlooked qualities such as affect.

These situational specifics are best understood via a relational perspective. This illuminates how the practices constituting circumstances involve not simply human individuals but also technologies and other things and, most important, the content, character, and quality of the relationships between them all. A relational perspective, however, does not simply apply to the level of circumstantial specifics, but also more broadly to that of organizations and meta-level systems. "High-tempo operations," for example, are a collective achievement constituted through multiple interactions between people and things and, as discussed previously, likely facilitated by the human predisposition for anticipation in addition to organizational/ institutional considerations. Analogous arguments apply to key insights of the organizational literature more generally. "Interactive complexity," "tight coupling," and "collective mindfulness" are all relational notions describing the form and character of relationships, or what might result from them. A key problem for those currently concerned with the achievement of sustainability is that this is not conceived relationally but rather either in non-human, ecological terms or in human ones (such as industrial transformation). Resolving this paradox should be a priority for those concerned with these matters but requires the transcendence of existing, dominant, discipline-bound perspectives.

Relational perspectives also direct attention to further considerations that have come under intense contemporary scrutiny, such as trust and temporality. These highlight an imperative for vigilant procedures that iteratively inform practical strategies that target circumstantial particulars on the basis of the alterations to system dynamics that they affect. Relational perspectives thus offer a powerful means of engaging the systemic dimensions of resilience in addition to underlining the qualities around which the resilience of circumstances revolve. However, while this chapter has sketched the breadth of insights that are capable of informing such strategies, it has also underlined the way that they tend to be constrained by affiliation to different paradigms and disciplines and how this works 
against interdisciplinary integration. This is a vulnerability that those concerned with systemic vulnerability and resilience should address as a priority.

\section{Notes}

1. Resilience is derived from the Latin word resilio, which means "to jump back" (Klein, Nicholls, \& Thomalla, 2003).

2. This undesirability of "negative resilience" presents an interesting contrast with "positive vulnerability"; i.e., vulnerability resulting in changes that are positive/ desirable (see the introduction of this book).

3. Recent research has focused attention on these embedded value judgments that until recently have tended to remain implicit. Key ideas are discussed in Smith and Stirling (2008) and Foxon, Reed, and Stringer (2008).

4. Others, like Carpenter et al. (2001), Dyer (1996), and Manyena (2006), have attempted such reviews.

5. The hospital data are derived from fieldwork of one of the authors in the United States and the Netherlands. The data are anonymized.

6. Lessick et al. (1992) proposes a "vulnerability model" as a framework for nursing practice. This model should assist nurses to understand individual-environment relationships.

7. These include Erik Hollnagel, Sydney Dekker, David Woods, and Nancy Leveson.

8. Our concern here is with these classic HROs, in which intense "high-tempo operations" are characteristic. The HRT literature, however, now extends to encompass many other kinds of organizations, such as nuclear power stations, which, as others note (see, e.g., Rijpma, 2003), have quite different characteristics and are not considered here.

9. That is, normal systems of authority dissolve with the most competent/skilled/ experienced taking command.

10. In short, the Swiss cheese model explains the occurrence of an accident as the result of the alignment of "holes" in the organizational defense system. These holes are weak spots in different parts of the organizational system, so their alignment provides an opportunity for an accident to happen.

11. Note that "sloppy management" in this case constitutes something of a caricature of the sophistication of Turner's attention to a far broader range of organiza- 
s a vulnerability that those esilience should address as a

2, which means "to jump back"

?nts an interesting contrast with $g$ in changes that are positive/

embedded value judgments that ideas are discussed in Smith and 3).

6), and Manyena (2006), have

me of the authors in the United ed.

'del" as a framework for nursing istand individual-environment

rid Woods, and Nancy Leveson.

in which intense "high-tempo swever, now extends to encomclear power stations, which, as sent characteristics and are not

in the most competent/skilled/

zcurrence of an accident as the ral defense system. These holes nal system, so their alignment

1stitutes something of a caricafar broader range of organiza-
12. Relatively rapid changes in ocean circulation patterns are thought likely to be central to this, the key concern being that the resultant change will prove less convivial to human civilization (and the main fauna) than current conditions (see maintenance of other flora and htm).

13. The Resilience Alliance (www.resalliance.org) and its journal Ecology and Society (www.ecologyandsociety.org) are the primary vehicles for this perspective. 


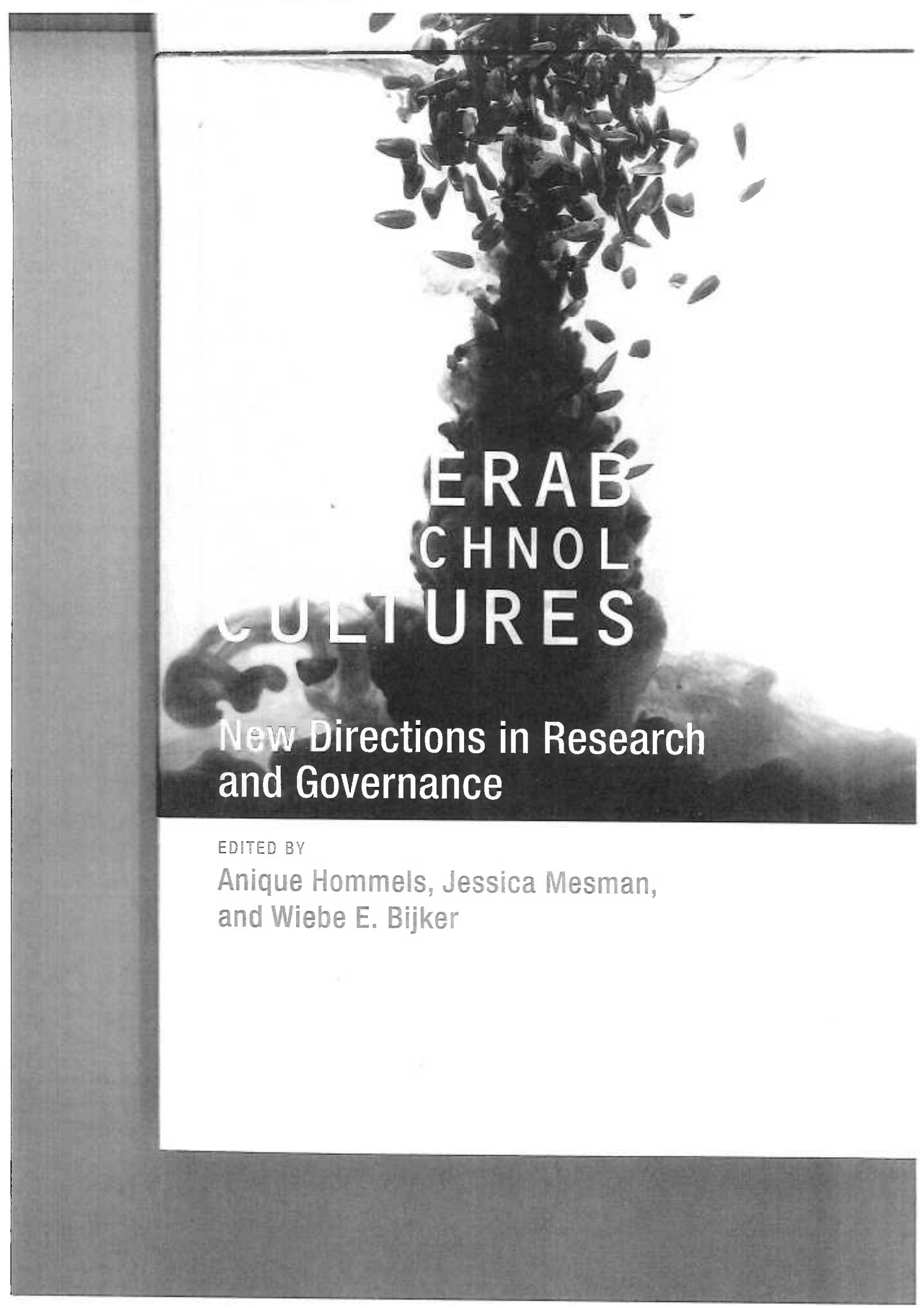

